
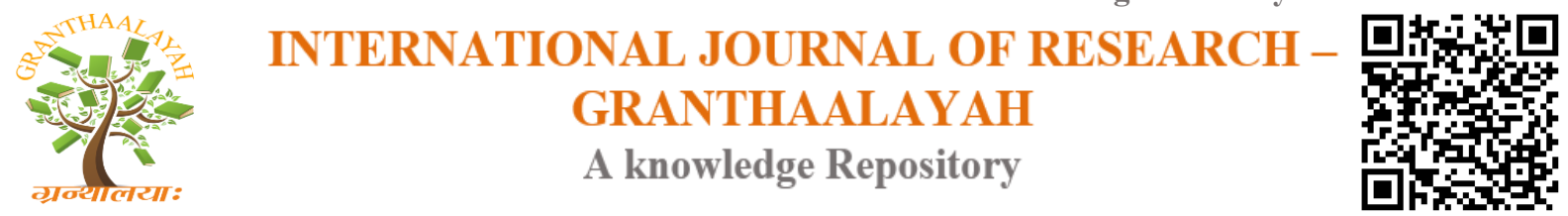

Management

\title{
RFID LIBRARY MANAGEMENT SYSTEM
}

\author{
Suganthy. $\mathbf{R}^{* 1}$ \\ ${ }^{* 1}$ Librarian, CMS College of Education, Coimbatore, INDIA
}

\begin{abstract}
This paper gives an overview of the current state of radio frequency identification (RFID) technology. Aside from a brief introduction to the principles of the technology, major current and envisaged fields of application, as well as advantages, and limitations of use are discussed. Radio frequency identification (RFID) is a generic term that is used to describe a system that transmits the identity (in the form of a unique serial number) of an object or person wirelessly, using radio waves. It's grouped under the broad category of automatic identification technologies. RFID is increasingly used with biometric technologies for security. In this paper Basic Principles of RFID technology along with its types are discussed.
\end{abstract}

Keywords:

RFID, Library Management System, digital data.

Cite This Article: Suganthy.R, "RFID LIBRARY MANAGEMENT SYSTEM" International Journal of Research - Granthaalayah, Vol. 4, No. 5: SE (2016): 87-91.

\section{INTRODUCTION}

RFID stands for Radio Frequency Identification. It is an electronic technology whereby digital data encoded in an RFID Tag (or transponder) is retrieved utilizing a reader. In contrast to bar code technology RFID systems do not require line-of-sight access to the tag in order to retrieve the tag's data, and they are well suited to harsh environments. The RFID reader is typically a microcontroller-based radio transceiver that powers the tag with a time-varying electromagnetic radio frequency (RF) field. When the RF field passes through the tag's antenna, AC voltage is generated in the antenna and rectified to supply power to the once powered; the tag can receive commands from the reader

Radio Frequency Identification (RFID) is a next generation of Auto Identification and Data Collection (AIDC) technology which helps to automate business processes in an Open environment with security. This automation can provide accurate and timely information without any human intervention. The new method for data collection and auto identification is called radio frequency identification of RFID that enable to automate the process of business. It also helps in large number identifications of objects that are tagged using the radio waves. This 
system based on library management system, allow easy transaction flow and also provide long term and immediate benefits for the library from the aspect of security and tractability.

\section{BACK GROUND AND RELATED WORKS}

There is a boom in the industry to use RFID technology in the recent years. Research and development in this field has made this technology to be used in supply chain management, attendance management, library management, automated toll collection etc. There are multiple RFID standards being used in the industry. The existence of these multiple standards helps the users of this technology to choose between various standards and choose the approach which best suits them and then implement it for communication between an interrogator (RFID reader) and the RFID tag. In more specific terms relating RFID to library, RFID in libraries was first developed and was proposed to the world in the late 1990s. RFID technology aimed at increasing the overall workflow in the library to the maximum as possible and to make everything like book issuing to book returning automatic. Singapore was the first country to introduce RFID in libraries and the Rockefeller University in New York was the first academic library in the U.S to make use of this technology. Farmington Community Library was the first public institution to use the RFID technology. Both Rockefellers University and Farmington started using RFID in1999. In Europe, the first public library to use RFID is the Hoogezand - Sappemeer, the Netherlands, in 2001, where borrowers were given options. It was proved in a survey that $70 \%$ people adapted to the RFID technology quickly. Overall, RFID technology is used in United States the most and then in United Kingdom and then in Japan. But there is an issue that this technology is still costly in today's market for the smaller organizations as compared to the larger organizations.

\section{RFID IN LIBRARIES}

Librarians are always known as early adopters of technology, as seen in case of Computer and later in case of Bar-codes. Later have seen standards like MARC and OCLC becoming popular among libraries for sharing bibliographic information with other libraries. In last decade have seen various library automation software being emerging as next wave of automation in libraries. Today patrons can visit library's catalogue any time they wish to with use of library's website. Library communities have always shown eagerness in experimenting new technology and have improved patron services today as a result of those efforts. RFID Technology is going to be next wave to automation in Library industry. RFID plays vital role in redefining the library process to make everyone's job easier right from patron to library staff. RFID provides a platform to automate most of the process performed by the library staff like Check in - check out, sorting, stock management and inventory. Library staff whose job is meant to be helping patron, use library resources at the fullest, is always busy handling the books. RFID helps to automate this process and provides them an opportunity to better utilize their time in serving patrons.

\section{BENEFITS OF RFID TECHNOLOGY IN LIBRARY}

\section{OVERVIEW}

- Fastest, easiest, most efficient way to track, locate \& manage library materials.

- Efficient Book circulation management. 
- Automatic Check-in and Check-out.

- Library inventory tracking in minutes instead of hours.

- Multiple books can be read simultaneously.

- Unique ID of the RFID tag prevents counterfeiting.

- Automated material handling using conveyor \& sorting systems.

- Facilitate inter library \& intra-library borrowing

- Taking inventory in a RFID based system doesn't require physical de-shelving \& shelving of library materials

\section{BENEFITS - LIBRARIES}

\section{STOCK MANAGEMENT}

- Operations such as managing material on the shelves, identifying missing \& miss shelved items and taking stocks regularly will be feasible

\section{IMPROVED PATRON SERVICES}

- Spending minimal time on circulation operations allows library staff to assist patrons

- Routine patron services are not disturbed even when libraries are facing staff shortages $\&$ budget cuts

\section{FLEXIBILITY AND MODULARITY}

- Ability to add newer products and features as finances and customer needs dictate

\section{SECURITY}

- Library item identification \& security is combined in to a single tag, thereby eliminating the need to attach an additional security strip

\section{BENEFITS - STAFF}

\section{LESS TIME NEEDED FOR CIRCULATION OPERATIONS}

- Implementing RFID will considerably reduce the amount of time required to issue, receive, transport, sort \& shelve library materials

\section{EFFICIENT INVENTORY MANAGEMENT}

- Inventory management can be done using a handheld reader without closing the library and is at least 20 times faster compared to existing barcode based system

\section{REDUCING REPETITIVE STRESS INJURIES (RSI)}

- RFID based system reduces repetitive scanning of individual items at the circulation desk during check in, check out and hence avoids RSI such as carpal tunnel syndrome

\section{BENEFITS - PATRONS}

- Patrons will spend less time waiting in check-out lines by using Self Check in - Check out systems. 
- Patrons find what they are looking for quickly \& easily

- Reminders for due dates allows patrons to submit borrowed materials in time

- Use of book drops \& return chutes for returning library material, allows for flexible timings

- RFID enabled patron cards allows for easy patron identification \& reduces errors

- Self-service enhances patron privacy

- Improved patron services even when libraries are facing staff shortage

\section{DISADVANTAGES OF RFID TECHNOLOGY IN LIBRARY}

\section{PROCUREMENT OF HARDWARE}

Sourcing of RFID hardware i.e. Readers, Tags \& Antenna needs to be done before starting anything else. Once the hardware specification and respective products are finalized specific read regions can be decided and implantation can be done.

\section{TAGGING BOOKS}

Each and every book needs to be tagged. The process needs 2-3 people continuously sticking tags to specific area of the book as decided earlier from the findings during the pilot test.

\section{INTEGRATING MIDDLEWARE}

Integrating middleware with the present library software systems and testing the results for improvements and errors.

\section{PERFORMING TEST CASES}

Predefined set of test cases will be performed in scenario based format to check out unit level and system level performance for accuracy and greater throughput.

\section{TRAINING STAFF}

This part of the implementation will include training staff on various aspects of RFID Technology and the new system in place. There will a demo which will include all the process in the system.

\section{PROCESS IMPROVEMENT}

The errors and improvements found out from the test cases will be revisited to make system perform in better way.

\section{CONCLUSION}

RFID technology is found to be a versatile technology in many real time applications, especially in library management system. This provides an intelligent library management, which creates better service quality with quick and effective benefits to both library management and students this technology can be applied to a system of volume. Either it may be a small departmental library or vast university library its effects are more obvious and applicable. This RFID technology also provides the facility of self-check for the library staff and non-returned books effectively. So, it is expected that this RFID technology will soon replace the presently existing 
technology method. The proposed system successfully implemented in our library and it is satisfactory working. The present work is intended to futher, by adding web technology. This web technology can provide additional technology of searching the books present in the library using their computers or mobile devices. For this online sevices a suitable web based system is under process in our university. For this purpose, the new features available in RFID and internet technologies are to be applied effectively, and planned to develop in this application.

\section{REFERENCES}

[1] ALA Library Fact Sheet Number 25 - RFID: A Brief Bibliography http://www.ala.org/ala/alalibrary/libraryfactsheet/alalibraryfactsheet $25 . \mathrm{htm}$

[2] Boss, Richard W. "RFID Technology for Libraries" http://www.ala.org/ala/pla/plapubs/technotes/rfidtechnology.htm

[3] ALA Office of Intellectual Freedom: http://www.ala.org/ala/oif/ifissues/rfid.htm

[4] Ward, Diane Marie. "Helping you Buy: RFID." Computers in Libraries 24:3

[5] Intellident RFID Library Installation (A Colchester Library Case Study)

[6] http://www.niso.org/publications/rp/RP-6-2008.pdf

[7] http://en.wikipedia.org/wiki/ National_Information_Standards_Organization_Circulation_Interchange_Protocol

[8] http://libraryrfid.typepad.com/libraryrfid/2004/04/new_email_list.html

[9] www.rfidwizard.com

[10] Josef, Schuermann. "Information Technology - Radio Frequency Identification (RFID) And The World Of Radio Regulations." http://www.iso.org/ 